\title{
Prediction of physicochemical properties of pummelo juice concentrates as a function of temperature and concentration
}

\begin{abstract}
The properties of pummelo juice were studied by measuring its chemical and physical composition. Pummelo fruit juice was freeze-concentrated to a concentration varying from 10 to $50{ }^{\circ}$ Brix for investigation at temperature ranging from 6 to $75{ }^{\circ} \mathrm{C}$. The fresh pummelo juice compositions in terms of moisture content, ash, fat, protein, fibre, carbohydrates, and vitamin $\mathrm{C}$ are comparable to existing literature. The water activity, $\mathrm{pH}$ and acidity were predictable linearly by its concentration measured in ${ }^{\circ}$ Brix. The density of pummelo juice was well-predicted using linear regressions with a single parameter (i.e., concentration), giving R2>0.983 and with a temperature at R2>0.921. The density of pummelo juice showed stronger dependence on its concentration than on the temperature. With multiple linear regressions, the density could be predicted by the equation, with an R2 of 0.9877 . As such, these predictions are useful in the juice processing industry as densities variant by concentration and temperature are important during the pasteurization process.
\end{abstract}

Keyword: Physicochemical; Density; Pummelo juice concentrate; Free-dried; Temperature; Total soluble solids 